\title{
RANCANGAN PERAWATAN BUS TRANSJAKARTA MENGGUNAKAN PENDEKATAN RELIABILITY CENTERED MAINTENANCE DI PERUM DAMRI SBU BUSWAY KORIDOR I \& VIII
}

\author{
Muhammad Aditya Putra dan Iveline Anne Marie \\ Laboratorium Sistem Produksi, Fakultas Teknologi Industri, Universitas Trisakti \\ e-mail: muhammadadityaputra14@gmail.com, ivelineannemarie@yahoo.com
}

\begin{abstract}
ABSTRAK
Transportasi telah berkembang pesat dan menjadi salah satu aspek penting dari kehidupan masyarakat saat ini. PERUM DAMRI SBU Busway Koridor I \& VIII adalah perusahaan transportasi yang memenuhi kebutuhan transportasi umum. Perusahaan membutuhkan 60 unit bus untuk beroperasi setiap hari. Pemeliharaan adalah hal yang penting untuk memastikan bahwa seluruh bus beroperasi dengan baik, untuk meminimalkan kegagalan komponen bus secara probabilitas. Tujuan dari penelitian ini adalah untuk memberikan metode pemeliharaan yang lebih baik dengan metode RCM (Reliability Centered Maintenance), yang bisa mengembangkan jadwal pemeliharaan. Penelitian ini menggunakan data komponen kegagalan Transjakarta Bus Koridor VIII dalam setahun. Tiga komponen penting untuk yang harus diperhatikan adalah rem, ban, dan kemudi. Tujuannya adalah memberikan kebijakan perawatan dengan pendekatan RCM. Titik dan tingkat risiko kritis masing-masing komponen diidentifikasi dengan metode Analisis Mode dan Efek Kegagalan Kritis (FMECA). Penggunaan metode RCM akan memberikan kebijakan perawatan untuk setiap komponen kritis dengan hasil tugas yang dijadwalkan. Kebijakan menyarankan perusahaan untuk mengganti komponen penting secara berkala dengan interval waktu tertentu sebelum terjadi kegagalan. Perubahan Interval perawatan preventif untuk rem, ban, dan kemudi pada 370 jam (8.064 km), 1988 jam (41.832 km), dan 661 jam (14.112 km). Jadwal ini memberikan peningkatan kehandalan rem dari 70,5\% (0,256 ke 0,961), 12,5\% untuk keandalan ban $(0604$ ke 0,186) dan 59,5\% untuk keandalan steering (0,193 ke 0,788).
\end{abstract}

Kata Kunci: Pemeliharaan, FMECA, RCM, Preventive Mengubah Interval, Keandalan

\begin{abstract}
Transportation has grew rapidly and be one of the important aspect of people's life nowadays. PERUM DAMRI SBU Busway Corridor I \& VIII is the transportation company that fulfill public transportation needs. The company needs 60 units of bus to operate every day. Maintenance is an important thing to make sure that the entire bus operates well, as to minimize the bus components failure probability.Based on the research, PERUM DAMRI SBU Busway I \& VIII Corridor still needs maintenance bus components correctively. The company already has a maintenance schedule just for oil replacement, but to schedule replacement of components not yet scheduled. According to previous statement, the research is to giving the better maintenance method with RCM (Reliability Centered Maintenance), which it could develop the maintenance schedule (Ramli, 2012). The research is using Transjakarta Bus Corridor VIII failure component data in a year. The 3 critical components to be concerned are brake, tire, and steering. The purpose is provide maintenance policy with RCM approach. The critical point and risk level of each components are being identified by Failure Mode and Effect Critically Analysis (FMECA). The use of RCM method will giving maintenance policy for each critical components with result of scheduled discard task. The policy suggest the company to change the critical components periodically with certain preventive changing interval before they are fail. The preventive changing interval for brake, tire, and steering are 370 hours (8064 km), 1988 hours (41832 km), and 661 hours (14112 km). This schedule gives the improvement to brake reliability of $70,5 \%$ (0.256 to 0.961$), 12.5 \%$ for tire reliability (0.604 to 0.186 ) and $59.5 \%$ for steering reliability (0.193 to 0.788$)$.
\end{abstract}

Keywords : Maintenance, FMECA, RCM, Preventive Changing Interval, Reliability

\section{PENDAHULUAN}

Transportasi saat ini sudah berkembang sangat pesat dan merupakan bagian terpenting yang tidak dapat dipisahkan dari kehidupan manusia. Setiap alat transportasi harus dalam kondisi yang baik saat beroperasi. Solusi yang digunakan untuk menjaga kondisi transportasi yang digunakan adalah dengan cara melakukan perawatan (maintenance) keseluruhan secara berkala sesuai dengan jadwal yang telah ditentukan. Perawatan alat transportasi yang digunakan penting dilakukan agardapat 
meminimalisir tingkat kerusakan dan dapat memperpanjang umur alat transportasi tersebut. PERUM DAMRI SBU Busway Koridor I \& VIII dalam melayani para pelanggan, harus menyiapkan 60 armada bus transjakarta tiap harinya dengan kondisi yang baik sehingga terhindar dari kerusakan. Oleh karena itu, untuk menjaga kondisi bus agar tetap baik saat dioperasikan maka dibutuhkan suatu proses perawatan (maintenance) terhadap komponen bus untuk mengurangi tingkat kerusakan agar dapat memenuhi kepuasan pengguna jasa transportasi busway. Namun PERUM DAMRI SBU Busway dalam melakukan perawatan pada setiap komponen bus masih bersifat corrective maintenance dimana perawatan dilakukan ketika komponen bus sudah mengalami kerusakan.

Preventive Maintenance merupakan perawatan yang dilakukan sebelum terjadinya kerusakan pada sebuah komponen. Tujuan digunakan preventive maintenance adalah mendeteksi lebih awal terjadinya kegagalan atau kerusakan, meminimalisasi terjadinya kegagalan yang disebabkan oleh kerusakan sistem. Reliability Centered Maintenance merupakan metode yang tepat sebagai solusi permasalahan yang terjadi untuk mengembangkan preventive maintenance yang terjadwal. RCM adalah proses untuk menentukan persyaratan pemeliharaan peralatan dalam konteks operasi dengan mengidentifikasi fungsi peralatan, penyebab kegagalan dan efek dari kegagalan [1]. Failure mode and effect criticality analysis (FMECA) berguna saat melakukan analisis menggunakan metode RCM. FMECA merupakan cara untuk mengevaluasi modus kegagalan potensial beserta efek dan penyebabnya secara sistematis dan terstruktur [2].

Berdasarkan pengamatan pendahuluan yang telah dilakukan, permasalahan yang dihadapi di PERUM DAMRI SBU Busway Koridor I \& VIII adalah pada masalah perawatan. Hal tersebut terjadi karena sering timbulnya kerusakan pada komponen bus bahkan harus sampai dilakukan penggantian sebelum umur pemakaian komponen habis. Namun jadwal untuk perawatan dan penggantian komponen bus saat ini masih belum tetap, dikarenakan perawatan dilakukan ketika komponen bus sudah mengalami kerusakan (corrective) sehingga belum ada jadwal tertentu untuk melakukan perawatan dan penggantian komponen yang rusak. Hal ini menyebabkan banyaknya kerusakan dini pada komponen bus sebelum umur pemakaiannya habis. Oleh karena itu diperlukan penjadwalan perawatan secara preventive pada setiap komponen bus agar dapat mengetahui kapan perawatan dan penggantian pada komponen bus yang rusak dapat dilakukan sehingga bus-bus akan tetap dalam kondisi yang baik saat beroperasi.

Adapun tujuan yang ingin dicapai pada penelitian ini berdasarkan permasalahan yang ada pada PERUM DAMRI SBU Busway Koridor I \& VIII adalah: memberikan usulan kebijakan perawatan dengan pendekatan Reliability Centered Maintenance.

\section{TINJAUAN PUSTAKA}

\section{Definisi Perawatan}

Maintenance adalah suatu kegiatan untuk merawat atau menjaga fasilitas atau peralatan pabrik dan mengadakan perbaikan atau penyesuaian atau penggantian yang diperlukan supaya terdapat suatu keadaan operasi produksi yang memuaskan sesuai dengan apa yang direncanakan, maka fasilitas dapat digunakan untuk proses produksi atau sebelum jangka waktu yang direncanakan tercapai [3].

\section{Reliability Centered Maintenance}

Reliability Centered Maintenance (RCM) diartikan sebagai suatu proses yang digunakan untuk menjelaskan apa yang harus dilakukan untk menjamin suatu asset fisik dapat berjalan dengan baik sesuai dengan keinginan penggunaanya [4].

Tahapan penerapan RCM diantaranya adalah: (1) Mengembangkan kegiatan analisis dengan failure mode and effect criticality analysis. (2) Menganalisis hasil FMECA. (3) Membuat RCM Information Worksheet pada lembar kerja I RCM. (4) Membuat RCM Decision Worksheet dengan bantuan RCM Decision Diagram. (5) Mengimplementasikan keputusan kebijakan perawatan berdasarkan 
RCM. (6) Melakukan evaluasi dari hasil usulan perawatan [4].

\section{Proactive Maintenance Task}

Proactive maintenance task adalah tindakan perawatan yang diambil sebelum kegagalan terjadi yang bertujuan untuk mencegah terjadinya kerusakan yang lebih serius. Dalam RCM predictive maintenance dimasukan dalam aktifitas scheduled on condition task, sedangkan preventive maintennce dimasukan kedalam scheduled restoration task ataupun scheduled discard task.

\section{RCM Decision Worksheet}

Reliability decision worksheet merupakan dokumen kerja penting kedua yang dipergunakan dalam aplikasi RCM untuk mencatat jawaban terhadap pertanyaan dalam decision diagram RCM. Pada decision worksheet akan menganalisis konsekuensi dai adanya kegagalan apakah berpengaruh terhadap keselamatan (S), lingkungan (E), atau berpengaruh terhadap kerugian operasional (O).

\section{Fault Tree Analysis}

Fault Tree Analysis adalah suatu teknik analisis desain keandalan (reliability) suatu desain sistem yang bermula atas dasar kesadaran terhadap efek kegagalan sistem, yang disebut "Top Event". Dalam analisis ini dijelaskan bagaiman top event disebabkan oleh kegagalan atau peristiwa pada level bawah baik secara individu maupun kombinasi.

Menurut Villemeur prinsip Fault Tree Analysis dalam melakukan analisis, yaitu: Mengidentifikasi berbagai kemungkinan kejadian kombinasi mengarahkan pada kejadian yang tidak diinginkan dan menghadirkan grafik kombinasi seperti struktur [5].

\section{Failure Mode and Effect Criticality Analysis (FMECA)}

Failure mode and effect criticality analysis (FMECA) berguna saat melakukan analisis menggunakan metode RCM. FMECA merupakan cara untuk mengevaluasi modus kegagalan potensial beserta efek dan penyebabnya secara sistematis dan terstruktur.
Langkah-langkah dasar dalam melakukan analisis menggunakan FMECA diantaranya adalah: mendefinisikan sistem untuk dianalisis, mengidentifikasi modus kegagalan yang berhubungan dengan kegagalan sistem, mengidentifkasi efek potensial dari modus kegagalan, menentukan dan merangking keseriusan dari setiap efek, menentukan semua akar penyebab potensial dari setiap modus kegagalan, dan mengidentifikasi tindakan rekomendasi setiap penyebab untuk mengurangi tingkat keparahan dari setiap kegagalan [2].

\section{Perhitungan Preventive Maintenance}

Distribusi kegagalan yang digunakan terdiri dari empat distribusi yaitu distribusi Eksponensial, distribusi Weibull, distribusi Normal, dan distribusi Lognormal [6]. Distribusi eksponensial. Reliability Function (Fungsi Keandalan)

$$
\begin{aligned}
& R(t)=\exp \left[-\int_{0}^{t} \lambda d t\right]=e^{-\lambda t}, t \geq 0, \\
& \text { MTTF }=\text { MTTR }=\int_{0}^{\infty} e^{-\lambda t} d t=\frac{1}{\lambda}
\end{aligned}
$$

Distribusi weibull. Reliability Function (Fungsi Keandalan):

$R(t)=e^{-\left(\frac{t}{\theta}\right)^{\beta}}$,

$\operatorname{MTTF}=\operatorname{MTTR}=\theta \Gamma\left(1+\frac{1}{\beta}\right)$

Distribusi normal. Reliability Function (Fungsi Keandalan):

$R(t)=1-\phi\left(\frac{t-\mu}{\sigma}\right)$,

$\mathrm{MTTF}=\mathrm{MTTR}=\mu$

Distribusi lognormal. Reliability Function (Fungsi Keandalan):

$R(t)=\int_{t}^{\infty} \frac{1}{\sqrt{2 \pi \sigma}} \exp \left(-\frac{1}{2} \frac{(t-\mu)^{2}}{\mu^{2}}\right)$,

$\mathrm{MTTF}=\mathrm{MTTR}=t_{m e d} E^{s^{\frac{s^{2}}{2}}}$ 


\section{Identifikasi Distribusi Kerusakan}

Identifikasi distribusi kerusakan terdiri dari dua perhitungan yaitu index of fit dan goodness of fit. Untuk perhitungan goodness of fit terdiri dari 3 pengujian yaitu uji kolmogorv smirnov untuk distribusi normal dan lognormal, uji bartlett untuk distribusi eksponensial dan uji mann untuk distribusi weibull [6].

\section{Interval Penggantian Pencegahan}

Model penentuan interval waktu peggantian pencegahan berdasarkan kriteria minimasi downtime yang digunakan adalah model Agre Replacement. Total downtime per unit waktu untuk penggantian pencegahan pada saat tp didenotasikan dengan $\mathrm{D}(\mathrm{tp})$, yakni [7]:

$$
\begin{aligned}
\mathrm{D}(\mathrm{tp}) & =\frac{\text { Total ekspektasi downtime per siklus }}{\text { ekspektasi panjang siklus }} \\
& =\frac{T_{p} R(t p)+(1-R(t p))}{\left.\left(t p+T_{p}\right) R(t p)+(M(t p))+T_{f}\right)(1-R(t p))}
\end{aligned}
$$

Nilai tingkat ketersediaan (availibility) dan interval penggantian pencegahan pada saat $\mathrm{D}(\mathrm{tp})$ minimum adalah: $\mathrm{A}(\mathrm{tp})=1-\mathrm{D}(\mathrm{tp}) \mathrm{min}$.

\section{Perhitungan Reliability Sesudah dan Sebelum Perawatan}

Peningkatan keandalan dapat ditempuh melalui perawatan pencegahan. Model keandalan berikut ini mengasumsikan sistem kembali ke kondisi semula setelah dilakukannya perawatan pencegahan. [6].

$$
R_{m}(t)=R(T)^{n} R(t-n T)
$$

\section{Dimana :}

$R_{m}(t) \quad$ : keandalan sistem setelah perawatan pencegahan

$R(T)^{\mathrm{n}} \quad$ : probabilitas nilai keandalan pada $\mathrm{n}$ interval perawatan,

$n \quad:$ jumlah perawatan yang dilakukan

$R(t-n T)$ : probabilitas nilai keandalan selama tnT unit waktu setelah tindakan perawatan pencegahan yang terakhir.

\section{METODOLOGI PENELITIAN}

Metodologi penelitian merupakan suatu proses kerangka pikir yang sistematis yang terdiri dari beberapa tahapan penelitian sehingga penelitian yang dilakukan lebih terarah untuk menuju kepada suatu solusi dan penyelesaian hasil yang lebih baik. Tahapan penelitian didalamnya terdiri dari penelitian pendahuluan, identifikasi permasalahan, studi pustaka, tujuan penelitian, pengumpulan data, pengolahan data, analisis hasil serta kesimpulan dan saran.

Pada tahapan penelitian pendahuluan dilakukan identifikasi hal-hal yang diperlukan pada penelitian ini yang digunakan untuk mengidentifikasi permasalahan yang ada di perusahaan. Dimana dari identifikasi yang dilakukan, diketahui bahwa permasalahan terletak pada sistem perawatan yang masih corrective.

Pada tahapan pengumpulan data, data yang didapat terdiri dari 2 jenis yaitu data primer dan data sekunder. Data primer yang didapat adalah hasil wawancara dengan pihak PERUM DAMRI SBU Busway. Data sekunder yang didapat adalah data umum perusahaan dan data historis kerusakan bus. Data yang didapat akan digunakan untuk melakukan pengolahan data.

Pada tahapan pengolahan data diawali dengan menentukan komponen kritis dengan menggunakan diagram pareto $80 \%$. Selanjutnya dilakukan tahapan perawatan menggunakan pendekatan RCM. Komponen kritis yang didapat diidentifikasi nilai kekritisannya dan tingkat resikonya dengan menggunakan failure mode and effect criticality analysis. Setelah pembuatan FMECA dilakukan pembuatan RCM information worksheet dan RCM decision worksheet untuk mendapatkan kebijakan yang diusulkan kepada pihak perusahaan. Dari hasil kebijakan yang diusulkan selanjutnya dilakukan perhitungan preventive maintenance untuk menghasilkan interval waktu penggantian pencegahan dan peningkatan nilai reliabilitas. Tahapan perhitungan preventive maintenance diawali dengan uji distribusi untuk memilih distribusi dengan melihat nilai index of fit tertinggi. Selanjutnya dilakukan uji kesesuaian distribusi dengan menggunakan goodness of fit untuk mengetahui apakah distribusi yang terpilih sudah sesuai. Selanjutnya dilakukan perhitungan untuk mencari nilai parameter- 
parameter MTTF dan MTTR dari masingmasing distribusi yang terpilih dengan menggunakan metode maximum likehood estimator. Selanjutnya dilakukan perhitungan interval waktu penggantian pencegahan dan waktu pemeriksaan untuk mendapatkan jadwal waktu penggantian pencegahan dan jadwal pemeriksaan komponen kritis. Dari perhitungan interval penggantian pencegahan dan pemeriksaan dapat dihasilkan nilai availability total. Terakhir dilakukan perhitungan reliabilitas sebelum dan sesudah perawatan pencegahan untuk mengetahui kenaikan tingkat reliabilitas pada masing-masing komponen kritis.

\section{HASIL DAN PEMBAHASAN}

PERUM DAMRI SBU Busway setiap harinya harus menyiapkan 60 armada bus untuk beroperasi. Karena bus harus dalam kondisi baik, diperlukan perawatan pencegahan untuk meminimalisirkan kerusakan yang sering timbul. Pada permasalahan ini digunakan pendekatan RCM untuk mengembangkan perawatan pencegahan. Karena perawatan yang dilakukan di PERUM DAMRI SBU Busway masih melakukan sistem perawatan yang corrective, dimana dalam melakukan perawatan dan penggantian komponen bus dilakukan ketika bus mengalami kerusakan dan tidak ada jadwal tertentu untuk melakukan perawatan dan penggantian komponen. Penggunaan RCM ini akan menghasilkan suatu kebijakan perawatan untuk komponen yang sering mengalami kerusakan. Kebijakan perawatan yang dihasilkan biasanya terdiri dari 3 jenis yaitu scheduled on condition task dimana kebijakan yang dilakukan hanyalah melakukan pemeriksaan pada komponen yang rusak, scheduled restoration task dimana kebijakan yang dilakukan adalah melakukan perbaikan secara menyeluruh sebelum masa komponen berakhir, dan scheduled discard task dimana kebijakan yang dilakukan adalah melakukan penggantian secara berkala sebelum umur pemakaian komponen habis. Untuk kebijakan scheduled restorationtask dan scheduled discard task selanjutnya harus dilakukan rencana perawatan pencegahan segera.

\section{Penentuan Komponen Kritis}

Penentuan komponen kritis dapat dilakukan dengan menggunakan diagram pareto 80\%. Data yang dibutuhkan untuk pembuatannya adalah data kerusakan komponen bus transjakarta. Dari diagram yang dihasilkan maka dapat diketahui komponen mana yang menjadi prioritas untuk diatasi. Berikut merupakan diagram untuk komponen kritis bus pada koridor VIII berdasarkan frekuensi kerusakan komponen.

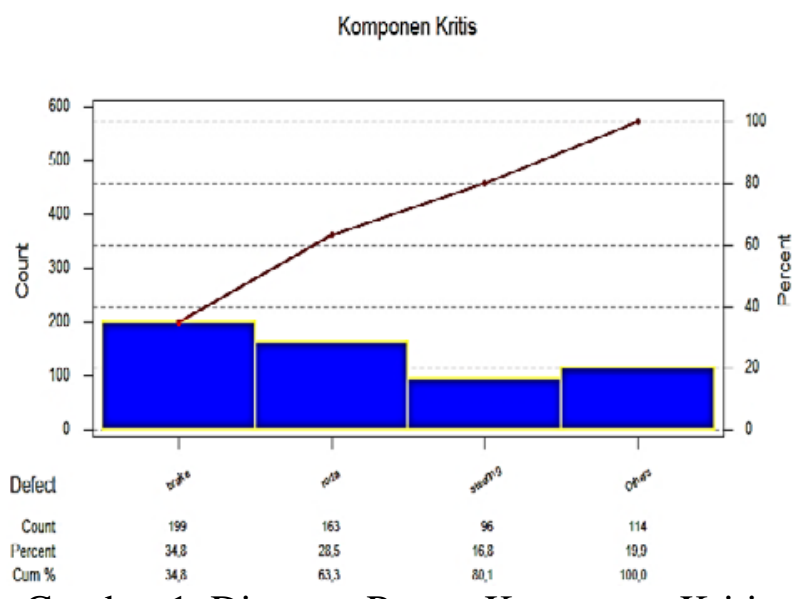

Gambar 1. Diagram Pareto Komponen Kritis

Berdasarkan diagram pareto diatas, maka didapat komponen kritis yang memiliki persentase kumulatif $80 \%$. Terdapat 3 komponen kritis yang dihasilkan antara lain komponen brake, roda, dan steering.

\section{Fault Tree Analyis}

Pembuatan fault tree diagram berguna untuk memudahkan mengetahui dan menganalisis modus kerusakan, komponen penyebab kerusakan, dan faktor kerusakan dari komponen kritis. Informasi-informasi yang ada pada fault tree diagram didapat dari hasil wawancara kepada kepala teknik PERUM DAMRI SBU Busway.

\section{FMECA}

FMECA digunakan untuk mengidentifiksi modus kegagalan yang paling berpotensi terjadi, efek kegagalan dari kerusakankerusakan yang dialamin oleh komponen kritis. Dasar-dasar data yang didapat untuk pembuatan FMECA didapat dari wawancara langsung dengan kepala teknik di PERUM DAMRI SBU 
Busway. Parameter yang dibutuhkan pada pembuatan FMECA adalah severity, occurance, dan detection.

Dari hasil Tabel 1 FMECA didapatkan bahwa komponen sistem brake dan roda memiliki resiko kritis dengan nilai kritikalnya adalah 300 dan komponen power steering memiliki resiko sangat tinggi denga nilai kritikalnya adalah 243.

\section{RCM Information Worksheet}

Setelah dicari komponen kritis menggunakan FMECA, selanjutnya adalah mengumpulkan informasi-informasi mengenai komponen kritis. Informasi tersebut dikumpulkan dengan cara membuat RCM information worksheet, informasi yang dikumpul berisikan fungsi, kegagalan fungsi, root cause failure analysis (modus kegagalan, mekanisme, alasan, akar penyebab) dan dampak kegagalan. Informasi-informasi tersebut didapat dari wawancara langsung kepada kepala teknik PERUM DAMRI SBU Busway.

\section{RCM Decision Worksheet}

RCM decision worksheet berguna untuk memberikan keputusan tentang kebijakan perawatan yang harus dilakukan dan diselesaikan. Untuk menentukan kebijakannya digunakan decision diagram sebagai dasar pertanyaan dan hasil jawabannya dimasukan kedalam RCM decision worksheet. Kebijakannya terdiri dari scheduled on condition task, scheduled restoration task dan scheduled discard task.

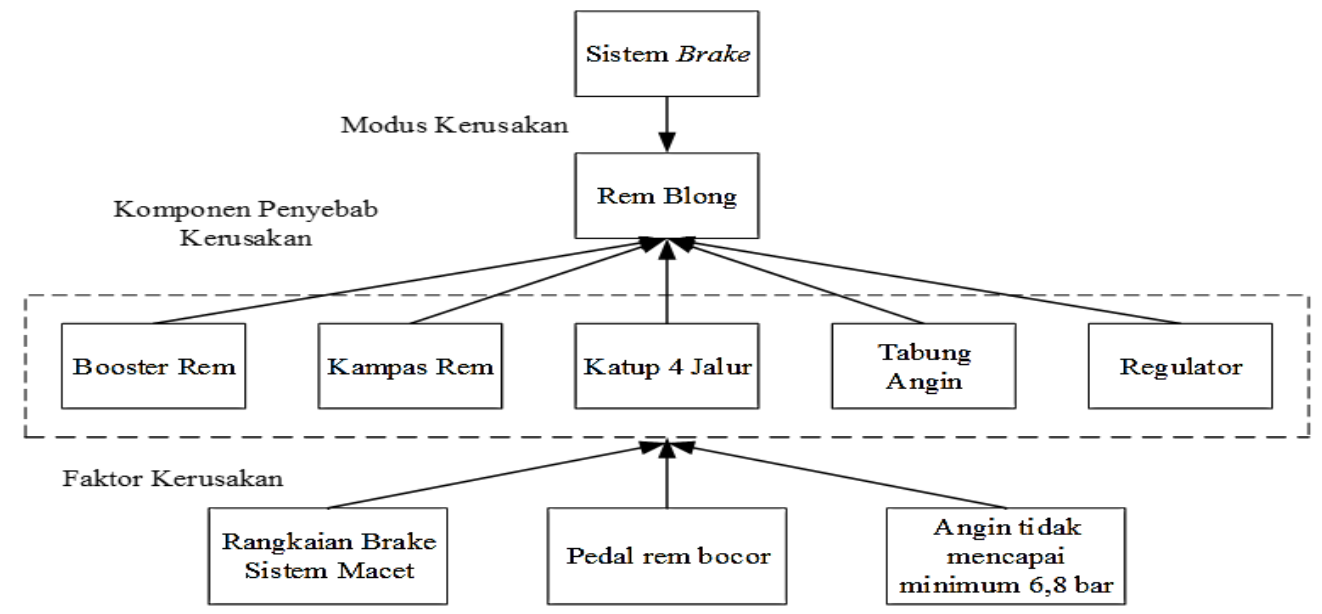

Gambar 2. Fault Tree Diagram Komponen Brake

Tabel 1. FMECA

\begin{tabular}{|c|c|c|c|c|c|c|c|c|c|c|}
\hline \multirow{2}{*}{ Komponen } & \multirow{2}{*}{ Fungsi } & \multirow{2}{*}{$\begin{array}{c}\text { Modul } \\
\text { Kegagalan } \\
\end{array}$} & \multirow{2}{*}{ Efek Kegagalan } & \multirow{2}{*}{$\begin{array}{l}\text { Penyebab } \\
\text { Kegagalan }\end{array}$} & \multirow{2}{*}{$\begin{array}{c}\text { Cara Medeteksi } \\
\text { Kegagalan }\end{array}$} & \multicolumn{4}{|c|}{ Kritikalitas } & \multirow{2}{*}{ Resiko } \\
\hline & & & & & & $\mathrm{S}$ & $\mathrm{O}$ & $\mathrm{D}$ & $\mathrm{C}$ & \\
\hline $\begin{array}{l}\text { Sistem } \\
\text { Break }\end{array}$ & $\begin{array}{l}\text { Memperlambat } \\
\text { gerakan roda } \\
\text { dan kecepatan }\end{array}$ & Rem Blong & $\begin{array}{l}\text { - Pedal rem } \\
\text { bocor } \\
\text { - Rem slip } \\
\text { - Angin tidak } \\
\text { mencapai min } \\
\text { 8-9 bar }\end{array}$ & $\begin{array}{l}\text { - Diafragma pada } \\
\text { booster rem } \\
\text { rusak } \\
\text { - Karat pada } \\
\text { selang capiler } \\
\text { roda } \\
\text { - Terdapat gemuk } \\
\text { pada kanvas rem }\end{array}$ & $\begin{array}{c}\text { Terdeteksi secara } \\
\text { langsung saat } \\
\text { digunakan }\end{array}$ & 10 & 10 & 3 & $\begin{array}{l}\text { Kritis } \\
(300)\end{array}$ & Unacceptable \\
\hline Roda & $\begin{array}{c}\text { Menjadikan } \\
\text { sistem kemudi } \\
\text { dapat bekerja }\end{array}$ & Roda rusak & $\begin{array}{l}\text { - } \text { Bearing roda } \\
\text { yang rusak } \\
\text { - As roda yang } \\
\text { rusak } \\
\text { - Jalan yang } \\
\text { rusak }\end{array}$ & $\begin{array}{l}\text { - Pelumasan yang } \\
\text { kurang rutin } \\
\text { - Dudukan } \\
\text { bearing longgar } \\
\text { - Karpet penutup } \\
\text { as roda robek }\end{array}$ & $\begin{array}{c}\text { Terdeteksi } \\
\text { dengan } \\
\text { mendengar suara } \\
\text { dan perputaran } \\
\text { roda }\end{array}$ & 10 & 10 & 3 & $\begin{array}{l}\text { Kritis } \\
(300)\end{array}$ & Unacceptable \\
\hline $\begin{array}{l}\text { Power } \\
\text { Steering }\end{array}$ & $\begin{array}{l}\text { Sebagai sistem } \\
\text { kemudi } \\
\text { kendaraan }\end{array}$ & $\begin{array}{c}\text { Stir } \\
\text { menjadi } \\
\text { berat }\end{array}$ & $\begin{array}{l}\text { - Power steering } \\
\text { bocor } \\
\text { - Tabung oli } \\
\text { steering bocor }\end{array}$ & $\begin{array}{l}\text { - Oli power } \\
\text { steering yang } \\
\text { sudah buruk } \\
\text { - Pemutaran roda } \\
\text { kemudi yang } \\
\text { sering mentok }\end{array}$ & $\begin{array}{c}\text { Terdeteksi secara } \\
\text { Langsung apakah } \\
\text { berat saat } \\
\text { digunakan dan } \\
\text { menimbulkan } \\
\text { bunyi aneh }\end{array}$ & 9 & 9 & 3 & $\begin{array}{l}\text { Sangat } \\
\text { tinggi }\end{array}$ & Unacceptable \\
\hline
\end{tabular}


Tabel 2. RCM Information Worksheet pada Komponen Kritis

\begin{tabular}{|c|c|c|c|c|c|c|c|c|c|c|c|}
\hline \multirow[b]{2}{*}{ No } & \multirow[b]{2}{*}{ Komponen } & \multirow{2}{*}{\multicolumn{2}{|c|}{ Fungsi }} & \multirow{2}{*}{\multicolumn{2}{|c|}{$\begin{array}{l}\text { Kegagalan } \\
\text { Fungsi }\end{array}$}} & \multicolumn{5}{|c|}{ Root Cause Failure Analysis (RCFA) } & \multirow{2}{*}{$\begin{array}{c}\text { Dampak } \\
\text { Kegagalan }\end{array}$} \\
\hline & & & & & & & $\begin{array}{l}\text { Modus } \\
\text { egagalan }\end{array}$ & Mekanisme & Alasan & Akar Penyebab & \\
\hline 1 & $\begin{array}{l}\text { Sistem } \\
\text { Brake }\end{array}$ & 1 & $\begin{array}{l}\text { Memperlambat } \\
\text { gerakan roda } \\
\text { dan kecepatan }\end{array}$ & A & $\begin{array}{l}\text { Rangakaian } \\
\text { sistem brake } \\
\text { mengalami } \\
\text { kemacetan }\end{array}$ & 1 & $\begin{array}{c}\text { Rem } \\
\text { blong }\end{array}$ & $\begin{array}{l}\text { Perlu dilakukan } \\
\text { pemeriksaan } \\
\text { dan } \\
\text { penggantian } \\
\text { pada komponen } \\
\text { rem }\end{array}$ & $\begin{array}{l}\text { Umur pemakaian } \\
\text { yang sudah terlewat } \\
\text { batas dan adanya } \\
\text { ketidaktelitian pada } \\
\text { saat melakukan } \\
\text { setting }\end{array}$ & $\begin{array}{l}\text { Diafragma } \\
\text { booster rem } \\
\text { mengalami } \\
\text { kerusakan dan } \\
\text { adanya gemuk } \\
\text { yang tersisa }\end{array}$ & $\begin{array}{c}\text { Terjadi } \\
\text { kebocoran } \\
\text { pada pedal } \\
\text { dan } \\
\text { mengalami } \\
\text { selip pada } \\
\text { saat rem } \\
\text { digunakan }\end{array}$ \\
\hline 2 & Roda & 1 & $\begin{array}{c}\text { Menjadikan } \\
\text { sistem kemudi } \\
\text { dapat bekerja }\end{array}$ & A & $\begin{array}{c}\text { Roda akan } \\
\text { menimbulkan } \\
\text { susra berisik } \\
\text { pada saat } \\
\text { bergerak }\end{array}$ & 1 & $\begin{array}{l}\text { Roda } \\
\text { rusak }\end{array}$ & $\begin{array}{c}\text { Dilakukan } \\
\text { penggantian } \\
\text { pada komponen } \\
\text { roda }\end{array}$ & $\begin{array}{c}\text { Umur pemakaian } \\
\text { yang sudah terlewat } \\
\text { batas }\end{array}$ & $\begin{array}{c}\text { Dudukan } \\
\text { bearing yang } \\
\text { longgar dan } \\
\text { kondisi karet } \\
\text { penutup as roda } \\
\text { yang sobek }\end{array}$ & $\begin{array}{c}\text { Terjadi } \\
\text { kerusakan } \\
\text { pada bagian } \\
\text { bearing dan } \\
\text { as roda }\end{array}$ \\
\hline 3 & $\begin{array}{c}\text { Power } \\
\text { Steering }\end{array}$ & 1 & $\begin{array}{l}\text { Sebagai sistem } \\
\text { kemudi dari } \\
\text { kendaraan }\end{array}$ & A & $\begin{array}{l}\text { Roda kemudi } \\
\text { akan sulit } \\
\text { digerakkan } \\
\text { karena keras }\end{array}$ & 1 & $\begin{array}{c}\text { Stir } \\
\text { menjadi } \\
\text { berat }\end{array}$ & $\begin{array}{c}\text { Dilakukan } \\
\text { pemeriksaan } \\
\text { dan } \\
\text { penggantian } \\
\text { pada komponen } \\
\text { steering }\end{array}$ & $\begin{array}{c}\text { Kondisi yang sudah } \\
\text { tidak baik lagi dan } \\
\text { pemakaian yang } \\
\text { terlalu kasar }\end{array}$ & $\begin{array}{c}\text { Oli power } \\
\text { steering sudah } \\
\text { tidak bagus dan } \\
\text { pemutaran roda } \\
\text { kemudi sering } \\
\text { mentok }\end{array}$ & $\begin{array}{c}\text { Power } \\
\text { steering } \\
\text { mengalami } \\
\text { kebocoran }\end{array}$ \\
\hline
\end{tabular}

Tabel 3. RCM Decision Worksheet pada Komponen Kritis

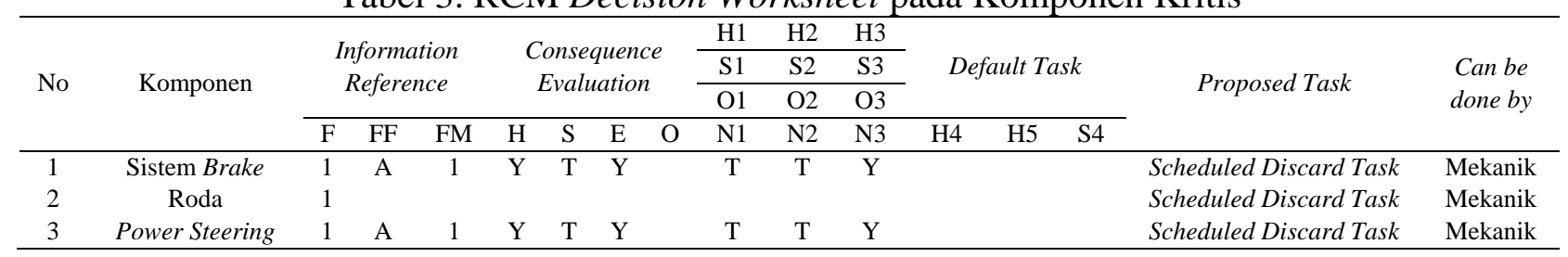

Dari Tabel 3 dapat dilihat bahwa untuk keseluruhan komponen kritis diberikan kebijakan scheduled discard task. Dimana kebijakan menganjurkan untuk melakukan penggantian komponen secara berkala berdasarkan interval waktu penggantian yang ditentukan.

Berikut merupakan contoh cara perhitungan dari selang waktu kerusakan dan selang waktu perbaikan pada komponen sistem brake bus 5111 :

- Contoh data yang dihitung adalah pada tanggal 20 Maret 2014 dan 22 Maret 2014.

- Pertama, dihitung selang waktu komponen sistem brake dapat beroperasi kembali setelah mengalami kerusakan pada tanggal 20 Maret 2014 hingga hari berakhir adalah 2,75 jam (pukul 21.15 sampai 00.00).

- Kedua, untuk selang waktu perbaikan komponen sistem brake mengalami kerusakan 40 menit atau 0,667 jam pada tanggal 20 Maret 2014 (pukul 20.35 sampai 21.15).

\section{Penentuan Jenis Distribusi Kerusakan}

Identifikasi distribusi kerusakan terdiri dari dua perhitungan yaitu index of fit dan goodness of fit. Metode yang digunakan untuk menghasilkan index of fit adalah least square curve fitting. Distribusi yang digunakan terdiri dari distribusi eksponensial, weibull, normal, dan lognormal. Untuk menguji kesesuaian (goodness of fit) pada ke 4 distribusi tersebut dilakukan dengan menggunakan tiga jenis uji kesesuaian, uji kolmogorov smirnov untuk distribusi normal dan lognormal, uji bartlett untuk distribusi eksponensial, dan uji mann untuk distribusi weibull.

\section{Perhitungan Parameter MTTF dan MTTR}

Perhitungan parameter MTTF dan MTTR sebelumnya telah dilakukan pada perhitungan index of fit, tetapi dilakukan kembali dengan menggunakan metode maximum likehood estimator (MLE) karena memberikan hasil estimasi yang lebih akurat. Tabel 5 merupakan hasil perhitungan distribusi kerusakan dan perhitungan parameter MTTF dan MTTR. 


\section{Perhitungan Interval Penggantian Pencegahan}

Setelah mendapatkan parameterparameter dari setiap komponen kritis, maka dapat dilakukan perhitungan interval penggantian berdasarkan minimasi downtime dengan menggunakan metode age replacement.

Dari Tabel 6 dapat diketahui hasil interval penggantian pencegahan dengan menggunakan model age replacement adalah sebesar 370 jam. Nilai tersebut didapat dari hasil nilai downtime (tp) yang paling minimum dengan nilai 0,0036005796577. A(tp) $=1-0,0036005796577$ $=0,99408249346$. Berikut merupakan hasil perhitungan interval penggantian pada komponen kritis.

Tabel 4. Selang Waktu Kerusakan dan Selang Waktu Perbaikan Komponen Sistem Brake Bus 5111 Bus 5111

\begin{tabular}{cccccc}
\hline No & Komponen & Awal Kerusakan & Akhir Perbaikan & TTF (jam) & TTR (jam) \\
\hline 1 & Brake & $3 / 16 / 1419: 40$ & $3 / 16 / 1420: 00$ & 0 & 0,333 \\
2 & Brake & $3 / 20 / 1420: 35$ & $3 / 20 / 1421: 15$ & 96,583 & 0,667 \\
3 & Brake & $3 / 22 / 1416: 25$ & $3 / 22 / 1416: 40$ & 43,167 & 0,25 \\
4 & Brake & $3 / 25 / 1416: 40$ & $3 / 26 / 1417: 00$ & 72 & 0,333 \\
5 & Brake & $3 / 26 / 1418: 10$ & $3 / 26 / 1420: 10$ & 25,167 & 2 \\
6 & Brake & $3 / 31 / 1415: 45$ & $3 / 31 / 1416: 25$ & 115,583 & 0,667 \\
7 & Brake & $4 / 9 / 1419: 30$ & $4 / 9 / 1420: 10$ & 219,083 & 0,667 \\
8 & Brake & $5 / 20 / 1417: 10$ & $5 / 20 / 1417: 30$ & 981 & 0,333 \\
9 & Brake & $6 / 2 / 1420: 05$ & $6 / 2 / 1420: 25$ & 314,583 & 0,333 \\
10 & Brake & $6 / 26 / 1416: 10$ & $8 / 25 / 1416: 40$ & 571,75 & 0,5 \\
11 & Brake & $7 / 6 / 1418: 25$ & $7 / 6 / 1418: 40$ & 241,75 & 0,25 \\
12 & Brake & $8 / 1 / 1415: 05$ & $8 / 1 / 1415: 25$ & 620,417 & 0,333 \\
13 & Brake & $8 / 3 / 1420: 15$ & $8 / 3 / 1420: 35$ & 52,833 & 0,333 \\
14 & Brake & $8 / 25 / 1416: 00$ & $8 / 25 / 1416: 20$ & 523,417 & 0,333 \\
15 & Brake & $11 / 19 / 1420: 30$ & $11 / 19 / 1420: 45$ & 2068,167 & 0,25 \\
16 & Brake & $1 / 16 / 1518: 25$ & $1 / 16 / 1519: 05$ & 1389,667 & 0,667 \\
17 & Brake & $1 / 27 / 1515: 50$ & $1 / 27 / 1516: 10$ & 260,75 & 0,333 \\
18 & Brake & $1 / 28 / 1520: 05$ & $1 / 28 / 1520: 25$ & 27,917 & 0,333 \\
19 & Brake & $2 / 2 / 1517: 40$ & $2 / 2 / 1519: 40$ & 117,25 & 2 \\
20 & Brake & $2 / 8 / 1519: 20$ & $2 / 8 / 1519: 50$ & 143,667 & 0,5 \\
21 & Brake & $2 / 16 / 1516: 25$ & $2 / 16 / 1518: 25$ & 188,583 & 2 \\
22 & Brake & $2 / 22 / 1519: 45$ & $2 / 22 / 1520: 15$ & 145,333 & 0,5 \\
23 & Brake & $2 / 23 / 1520: 10$ & $2 / 13 / 1520: 50$ & 23,917 & 0,667 \\
24 & Brake & $2 / 28 / 1515: 30$ & $2 / 28 / 1516: 00$ & 114,667 & 0,5 \\
\hline
\end{tabular}

Tabel 5. Hasil Perhitungan Distribusi Kerusakan dan Parameter MTTF MTTR

\begin{tabular}{ccccc}
\hline & \multicolumn{3}{c}{ INDEX OF FIT } \\
\hline \multirow{2}{*}{ Distribusi } & IoF TTF & IoF TTR & Distribusi Terpilih \\
\cline { 3 - 5 } & & 0,7832 & TTF & TTR \\
\hline Normal & 0,8151 & 0,9044 & Lognormal & Eksponensial \\
Lognormal & 0,9915 & 0,9068 & & \\
Eksponensial & 0,9622 & 0,829 & & \\
Weibull & 0,9599 & Roda Bus 5078 & & \\
\hline & & \multirow{2}{*}{ IoF TTR } & Distribusi Terpilih \\
\hline Distribusi & IoF TTF & & & TTR \\
\hline Normal & 0,669 & 0,9041 & Lognormal & Eksponensial \\
Lognormal & 0,947 & 0,9043 & & \\
Eksponensial & 0,8431 & 0,9238 & & \\
Weibull & 0,9448 & 0,8836 &
\end{tabular}


Rancangan Perawatan Bus Transjakarta Menggunakan Pendekatan Reliability Centered Maintenance di Perum DAMRI SBU Busway Koridor I \& VIII

Muhammad Aditya Putra dan Iveline Anne Marie

Lanjutan Tabel 5. Hasil Perhitungan Distribusi Kerusakan dan Parameter MTTF MTTR INDEX OF FIT

\begin{tabular}{|c|c|c|c|c|}
\hline \multicolumn{5}{|c|}{ Steering Bus 5078} \\
\hline \multirow{2}{*}{ Distribusi } & \multirow{2}{*}{ IoF TTF } & \multirow{2}{*}{ IoF TTR } & \multicolumn{2}{|c|}{ Distribusi Terpilih } \\
\hline & & & TTF & TTR \\
\hline Normal & 0,84 & 0,6752 & \multirow{4}{*}{ Lognormal } & \multirow{4}{*}{ Weilbull } \\
\hline Lognormal & 0,9847 & 0,6767 & & \\
\hline Eksponensial & 0,9681 & 0,4491 & & \\
\hline Weibull & 0,962 & 0,7655 & & \\
\hline \multicolumn{5}{|c|}{ MAXIMUM LIKEHOOD ESTIMATOR } \\
\hline Distribusi & Data & Distribusi Terpilih & \multicolumn{2}{|c|}{ Distribusi Terpilih } \\
\hline \multirow{6}{*}{$\begin{array}{l}\text { Brake } \\
\text { (5111) }\end{array}$} & \multirow{3}{*}{ TTF } & \multirow{3}{*}{ Lognormal } & $\mathrm{t}_{\mathrm{med}}$ & 174,6353 \\
\hline & & & $\mathrm{S}$ & 1,2237 \\
\hline & & & MTTF & 390,3307 \\
\hline & \multirow{3}{*}{ TTR } & \multirow{3}{*}{ Lognormal } & $t_{\text {med }}$ & 0,4971 \\
\hline & & & $\mathrm{S}$ & 1,9138 \\
\hline & & & MTTR & 2775,7701 \\
\hline \multirow{5}{*}{$\begin{array}{l}\text { Roda } \\
\text { (5111) }\end{array}$} & \multirow{3}{*}{ TTF } & \multirow{3}{*}{ Lognormal } & $t_{\text {med }}$ & 142,4798 \\
\hline & & & S & 1,9138 \\
\hline & & & MTTF & 2775,7701 \\
\hline & \multirow{2}{*}{ TTR } & \multirow{2}{*}{ Lognormal } & $\lambda$ & 1,341 \\
\hline & & & MTTR & 0,7457 \\
\hline \multirow{6}{*}{$\begin{array}{c}\text { Steering } \\
\text { (5111) }\end{array}$} & \multirow{3}{*}{ TTF } & \multirow{3}{*}{ Lognormal } & $t_{\text {med }}$ & 224,1241 \\
\hline & & & $\mathrm{S}$ & 1,3718 \\
\hline & & & MTTF & 735,7482 \\
\hline & \multirow{3}{*}{ TTR } & \multirow{3}{*}{ Weibull } & $\beta$ & 12,7794 \\
\hline & & & $\theta$ & 2,962 \\
\hline & & & MTTR & 2,8426 \\
\hline
\end{tabular}

Tabel 6. Interval Penggantian Pencegahan Komponen Sistem Brake Bus 5111

\begin{tabular}{ccccccc}
\hline Tp (jam) & $\mathrm{F}(\mathrm{T})$ & $\mathrm{R}(\mathrm{tp})$ & $\mathrm{Tp} * \mathrm{R}(\mathrm{tp})$ & $\mathrm{Tf} * \mathrm{~F}(\mathrm{tp})$ & $\mathrm{M}(\mathrm{tp})$ & $\mathrm{D}(\mathrm{tp})$ \\
\hline 380 & 0,7374 & 0,2626 & 0,0954 & 0,2679 & 0,993054795865 & 0,0036011807374 \\
379 & 0,7367 & 0,633 & 0,09566 & 0,26764 & 0,993155046609 & 0,0036011065363 \\
378 & 0,73599 & 0,26401 & 0,09591 & 0,26739 & 0,993264644781 & 0,0036009475037 \\
377 & 0,73528 & 0,26472 & 0,09617 & 0,26713 & 0,993370089365 & 0,0036008392783 \\
376 & 0,73457 & 0,26543 & 0,09643 & 0,26687 & 0,993471345856 & 0,0036007818515 \\
375 & 0,73386 & 0,26614 & 0,09669 & 0,26661 & 0,993568379467 & 0,0036007752190 \\
374 & 0,73314 & 0,26686 & 0,09695 & 0,26635 & 0,993674708623 & 0,0036006859080 \\
373 & 0,73242 & 0,26758 & 0,09721 & 0,26609 & 0,993776773531 & 0,0036006481053 \\
372 & 0,7317 & 0,2683 & 0,09747 & 0,26583 & 0,993874538448 & 0,0036006618082 \\
371 & 0,73097 & 26903 & 0,09774 & 0,26556 & 0,993981565266 & 0,0036005946230 \\
370 & 0,73024 & 0,26976 & 0,098 & 0,2653 & 0,994084249346 & 0,0036005796577 \\
369 & 0,72951 & 0,27049 & 0,09827 & 0,26503 & 0,994182553958 & 0,0036006169115 \\
368 & 0,72878 & 0,27122 & 0,09853 & 0,26477 & 0,994276442067 & 0,0036007063883 \\
367 & 0,72804 & 0,27196 & 0,0988 & 0,2645 & 0,994379534449 & 0,0036007171198 \\
366 & 0,7273 & 0,2727 & 0,09907 & 0,26423 & 0,994478165455 & 0,0036007807907 \\
365 & 0,72656 & 0,27344 & 0,09934 & 0,26396 & 0,994572297018 & 0,0036008974073 \\
364 & 0,72581 & 0,27419 & 0,09961 & 0,26369 & 0,994675594916 & 0,0036009370586 \\
363 & 0,72506 & 0,27494 & 0,09989 & 0,26341 & 0,994868514049 & 0,0036010303733 \\
362 & 0,72431 & 0,27569 & 0,10016 & 0,26314 & 0,994868514049 & 0,0036011773603 \\
361 & 0,72355 & 0,27645 & 0,10043 & 0,26287 & 0,994971807747 & 0,0036012491600 \\
\hline
\end{tabular}

Dari hasil Tabel 7 dapat dilihat bahwa interval waktu penggantian komponen sistem brake adalah 16 hari, komponen roda adalah 83 hari dan komponen power steering adalah 28 
hari. Untuk nilai minimum D(tp) dan Availability (tp) akan digunakan untuk mengetahui availability total pada setiap komponen kritis.

\section{Perhitungan Interval Pemeriksaan}

Perhitungan interval pemeriksaan dilakukan untuk mengetahui kapan waktu pemeriksaan yang akan dilakukan untuk setiap komponen kritis.

Dari Tabel 8 didapati interval waktu pemeriksaan untuk komponen sistem brake adalah 10 hari dengan frekuensi pemeriksaan optimal 3 kali dalam sebulan, komponen roda adalah 14 hari dengan frekuensi pemeriksaan optimal 2 kali dalam sebulan dan komponen power steering adalah 7 hari dengan frekuensi pemeriksaan optimal 4 kali dalam sebulan.

Nilai downtime dan availability setelah penggantian pencegahan dan pemeriksaan sudah dapat diketahui. Nilai availability didapat dengan mengkalikan nilai availability interval pemeriksaan dengan nilai availabiity interval penggantian pencegahan.

Dari Tabel 9 didapati hasil availability total untuk komponen sistem brake sebesar
0,995, komponen roda sebesar 0,993 dan komponen power steering sebesar 0,976.

\section{Perhitungan Reliabilitas Sebelum dan Sesudah Perawatan Pencegahan}

Perhitungan reliabilitas ini ditujukan untuk mengetahui kenaikan nilai reliabilitas dari sebelum perawatan dengan sesudah perawatan. Tingkat kenaikan keandalan yang dihasilkan memiliki satuan persen.

Dari hasil Tabel 10 terjadi peningkatan nilai reliabilitas untuk keseluruhan komponen kritis. Untuk komponen sistem brake mengalami kenaikan sebesar 70,5\%, komponen roda mengalami kenaikan sebesar $12,5 \%$ dan komponen power steering mengalami kenaikan sebesar 59,5\%.

Dari hasil perhitungan interval penggantian pencegahan dan interval pemeriksaan, dapat dilakukan usulan penjadwalan untuk melakukan perawatan pencegahan. Berikut merupakan usulan penjadwalan.

Tabel 7. Hasil Perhitungan Interval Penggantian Komponen Kritis

\begin{tabular}{ccccc}
\hline Komponen & Age Replacement (jam) & Age Replacement (hari) & Minimum D(tp) & Availability (tp) \\
\hline Sistem Brake & 370 & 16 & 0,00360058 & 0,99639942 \\
Roda & 1988 & 83 & 0,004419986 & 0,995580014 \\
Power Streering & 661 & 28 & 0,019628972 & 0,980371028 \\
\hline
\end{tabular}

Tabel 8. Hasil Perhitungan Interval Pemeriksaan Komponen Kritis

\begin{tabular}{ccccccc}
\hline Komponen & $\mathrm{k}$ & $\mu$ & $\mathrm{i}$ & $\begin{array}{c}\text { Frekwensi } \\
\text { Pemeriksaan } \\
\text { Optimal }\end{array}$ & $\begin{array}{c}\text { Interval Waktu } \\
\text { Pemeriksaan } \\
\text { Optimal 1 (jam) }\end{array}$ & $\begin{array}{c}\text { Interval Waktu } \\
\text { Pemeriksaan } \\
\text { Optimal 1 (hari) }\end{array}$ \\
\hline Sistem Brake & 1,8462 & 1310,21 & 2856 & 3 & 159 & 10 \\
Roda & 1,4615 & 638,326 & 1428 & 2 & 238 & 14 \\
Power Streering & 1,3846 & 166,242 & 1428 & 4 & 119 & 7 \\
\hline
\end{tabular}

Tabel 9. Hasil Perhitungan Availibility dan Downtime Komponen Kritis

\begin{tabular}{cccccccc}
\hline Komponen & $\mathrm{k}$ & $\mu$ & $\mathrm{i}$ & $\mathrm{D}(\mathrm{n})$ & $\mathrm{A}(\mathrm{n})=1-\mathrm{D}(\mathrm{n})$ & $\begin{array}{c}\text { Availability } \\
\text { Penggantian } \\
\text { Pencegahan }\end{array}$ & Availability \\
\hline Sistem Brake & 1,8462 & 1310,21 & 2856 & 0,00152 & 0,998479897 & 0,99639942 & 0,99488479 \\
Roda & 1,4615 & 638,326 & 1428 & 0,00255 & 0,997454619 & 0,995580014 & 0,993045883 \\
Power Streering & 1,3846 & 166,242 & 1428 & 0,00488 & 0,995116648 & 0,980371028 & 0,975583531 \\
\hline
\end{tabular}


Rancangan Perawatan Bus Transjakarta Menggunakan Pendekatan Reliability Centered Maintenance di Perum DAMRI SBU

Busway Koridor I \& VIII

Muhammad Aditya Putra dan Iveline Anne Marie

Tabel 10. Hasil Perhitungan Reliabilitas Sebelum dan Sesudah Perawatan pada Komponen Kritis Nilai Reliabilitas

\begin{tabular}{cccc} 
Komponen & $\begin{array}{c}\text { Sebelum Penggantian } \\
\text { Pencegahan }\end{array}$ & $\begin{array}{c}\text { Sesudah Penggantian } \\
\text { Pencegahan }\end{array}$ & $\begin{array}{c}\text { Peningkatan } \\
\text { Reliability }\end{array}$ \\
\hline Sistem Brake & 0,5550544 & 0,960577773 & $70,5 \%$ \\
Roda & 0,060377031 & 0,185791134 & $12,5 \%$ \\
Power Streering & 0,193103353 & 0,788278628 & $59,5 \%$ \\
\hline
\end{tabular}

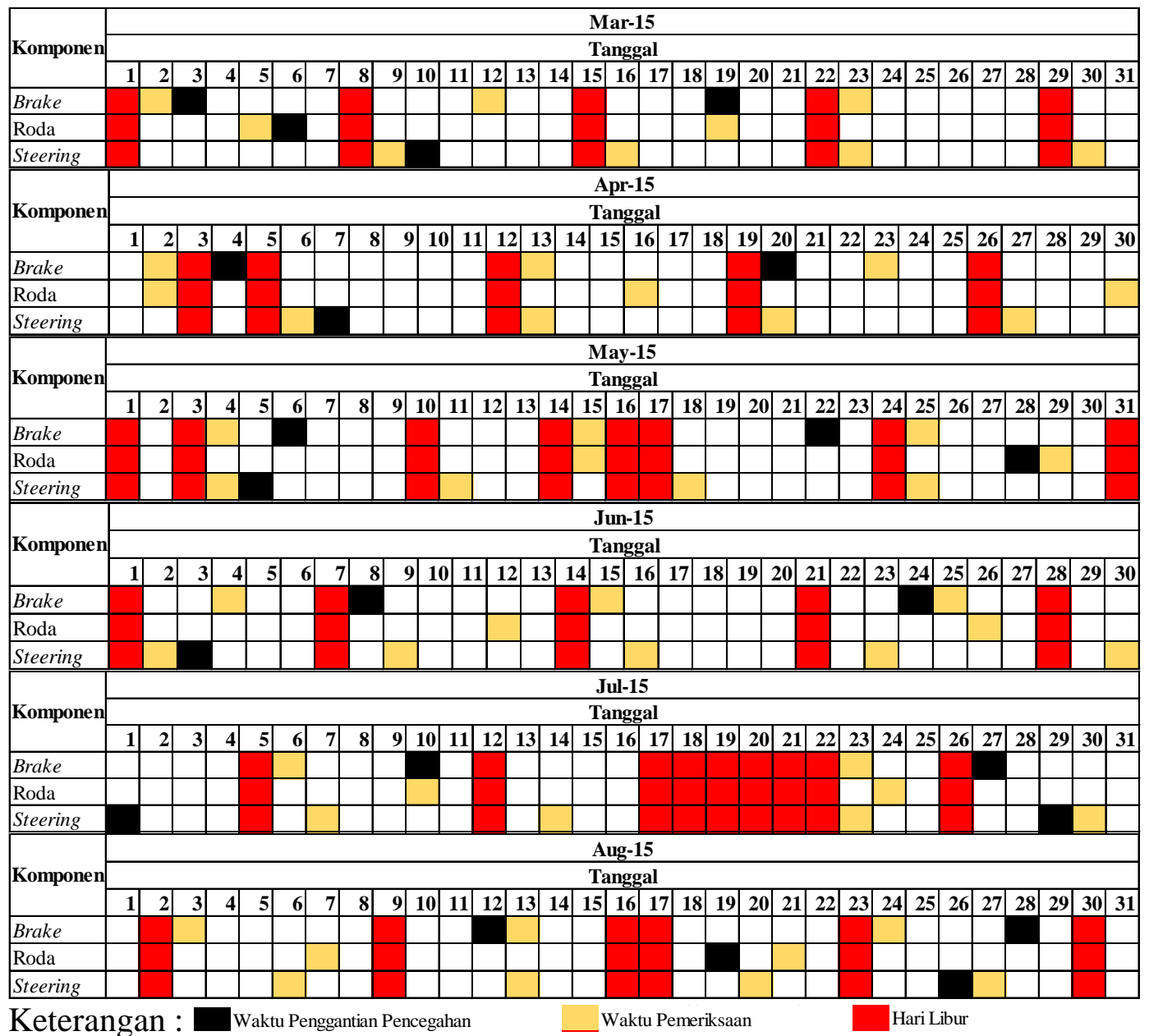

Gambar 3. Penjadwalan Penggantian Pecegahan dan Pemeriksaan

Tabel 11. Usulan Jadwal Penggantian Komponen (Konversi ke Kilometer)

\begin{tabular}{cccccc}
\hline Komponen & $\begin{array}{c}\text { Waktu Penggantian } \\
(\text { jam })\end{array}$ & $\begin{array}{c}\text { Waktu Penggantian } \\
(\text { jam })\end{array}$ & $\begin{array}{c}\text { Jarak Tempuh } \\
(\mathrm{km})\end{array}$ & $\begin{array}{c}\text { Trayek/hari } \\
(\mathrm{max})\end{array}$ & $\begin{array}{c}\text { Usulam Penggantian } \\
(\mathrm{km})\end{array}$ \\
\hline Brake & 370 & 16 & 28 & 9 & 8064 \\
Roda & 1988 & 83 & 28 & 9 & 41832 \\
Steering & 661 & 28 & 28 & 9 & 14112 \\
\hline
\end{tabular}

Tabel 12. Usulan Jadwal Pemeriksaan Komponen (Konversi ke Kilometer)

\begin{tabular}{cccccc}
\hline Komponen & $\begin{array}{c}\text { Waktu Penggantian } \\
\text { (jam) }\end{array}$ & $\begin{array}{c}\text { Waktu Penggantian } \\
(\text { jam })\end{array}$ & $\begin{array}{c}\text { Jarak Tempuh } \\
(\mathrm{km})\end{array}$ & $\begin{array}{c}\text { Trayek/hari } \\
(\mathrm{max})\end{array}$ & $\begin{array}{c}\text { Usulam Penggantian } \\
(\mathrm{km})\end{array}$ \\
\hline Brake & 159 & 10 & 28 & 9 & 5040 \\
Roda & 238 & 14 & 28 & 9 & 7056 \\
Steering & 119 & 7 & 28 & 9 & 3528 \\
\hline
\end{tabular}


Dari penjadwalan di atas dapat dilihat interval penggantian dan pemeriksaan. Untuk komponen brake dilakukan penggantian komponen selama 16 hari sekali dan pemeriksaannya selama 10 hari sekali, komponen roda dilakukan penggantian komponen selama 83 hari sekali dan pemeriksaannya selama 14 hari sekali dan komponen steering dilakukan penggantian komponen selama 28 hari sekali dan pemeriksaannya selama 7 hari sekali. Perawatan dan penggantian biasanya dilakukan PERUM DAMRI SBU Busway pada malam hari.

Dari interval waktu penggantian pencegahan dan pemeriksaan, waktu penggantian dan pemeriksaan dapat dikonversikan ke satuan kilometer untuk lebih mudah terkontrol oleh bagian departemen perawatan.

\section{KESIMPULAN}

Berdasarkan pengamatan yang telah dilakukan pada PERUM DAMRI SBU Busway dapat disimpulkan bahwa: dengan menggunakan pendekatan RCM dapat dihasilkan suatu kebijakan perawatan untuk komponen kritis yang diamati. Komponen kritis itu sendiri didapat dengan menggunakan diagram pareto berdasarkan frekuensi kerusakan komponen. Komponen kritis yang didapat antara lain : komponen sistem brake, roda dan power steering. Dari hasil pendekatan RCM tersebut didapat bahwa untuk ketiga komponen kritis yang diamati diberikan kebijakan perawatan yaitu scheduled discard task. Kebijakan tersebut mengharuskan untuk dilakukan penggantian komponen secara berkala berdasarkan interval waktu penggantian tertentu sebelum umur komponen habis. Interval waktu penggantian didapatkan dari perhitungan preventive maintenance, dimana hasil yang didapat untuk interval penggantian antara lain: komponen sistem brake: 370 jam atau 16 hari sekali, roda: 1988 jam atau 83 hari sekali dan power steering: 661 jam atau 28 hari sekali. Dari hasil interval waktu penggantian setiap komponen kritis, didapatkan peningkatan nilai reliabilitas dari sebelum dan sesudah perawatan pencegahan antara lain: komponen sistem brake: 70,5 \% (dari 0,256 menjadi 0,961), roda: $12,5 \%$ (dar 0,060 menjadi 0,186 ) dan power steering: 59,5 \% (dari 0,193 menjadi 0,788).

\section{DAFTAR PUSTAKA}

[1] Ramli, R., Arffin, M.N. 2012. Reliability Centered Maintenance in Schedule Improvement of Automative Assembly Industry. American Journal of Applied Science. Vol. 9 No.8, p 1232 - 1236.

[2] Ysaad, B., M. Khiat, A. Chaker. 2014. Reliability centered maintenance optimization for power distribution system. International Journal of Electric Power and Energy Systems. Vol 55. p 108 $-115$.

[3] Assauri, Sofjan. 2008. Manajemen Produksi dan Operasi. Edisi Revisi. Jakarta: Fakultas Ekonomi UI.

[4] Moubray, J. 1991. Reliability Centered Maintenance II. New York : Industrial Press Inc.

[5] Villemeur, Willey And Sons. 1992. Reliability, Avalability, Maintanability And Safety Assessment. Vol I. Methods And Teqniques.

[6] Ebeling, Charles E, 1997. An Introduction to Reliability and Maintainability Engineering. Singapore : McGraw-Hill.

[7] Jardine, A. K. S. 1973. Maintenance, Replacement and Reliability. London : Pitman Publishing. 